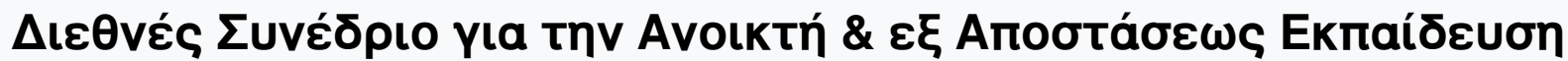

Tóp. 10, Ap. 2A (2019)

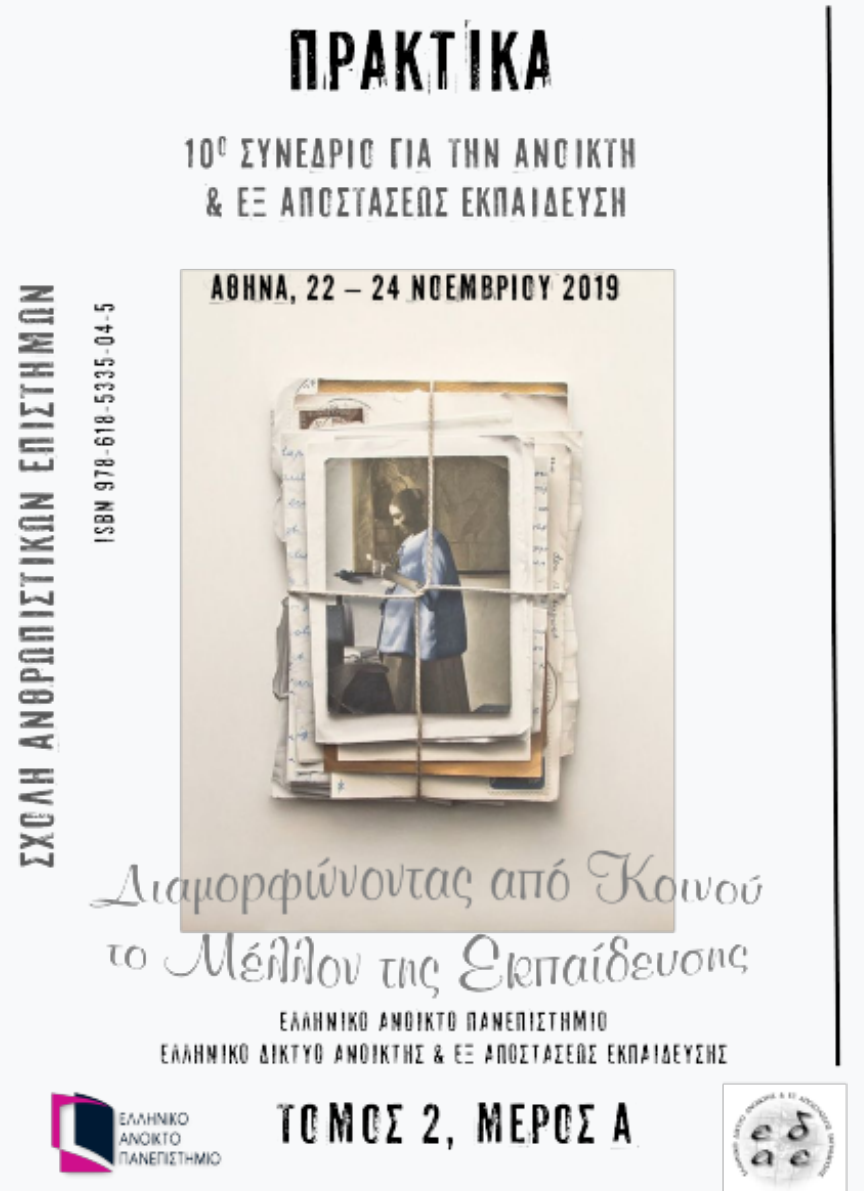

Designing Infographics in a Higher Education context: content and aesthetics in a timeline layout

Olga Fragou, Maria Papadopoulou

doi: $10.12681 /$ icodl.2164 


\title{
Designing Infographics in a Higher Education context: content and aesthetics in a timeline layout
}

\author{
Fragou Olga \\ Hellenic Open University, Academic Tutor \\ fragkou.olga@ac.eap.gr
}

Papadopoulou Maria

Hellenic Open University, Aristotle University of

Thessaloniki, Associate Professor, papadopoulou.maria@ac.eap.gr

\begin{abstract}
Infographics as data visualization practices, illustrate information creating a visual narrative, challenging students to visually communicate ideas and develop respective digital skills. Visual communication literature acknowledges appearance and explanation as important attributes of information graphics; however little research has been conducted so as to determine how these properties function. This paper aims to address criteria for the efficacy of infographics: an evaluation rubric has been used to examine appearance and explanation based on aesthetic and content values. Twelve (12) timeline infographics have been collected from Higher Education students who produced their digital artifacts in the context of the Module 'Design and development of Educational Material and Digital Media' which is a Thematic Unit of Masters Program 'Language Education for Refugees and Migrants' of the Hellenic Open University (HOU). Analyzed data revealed characteristics of timeline infographics regarding functionality and esthetics.
\end{abstract}

Keywords: infographics, adult learning, visual literacy, digital design, open source software, Higher Education, reflective practice, evaluation

\section{Introduction}

The contemporary concept of education supports rather the development of reading literacy (the understanding of letters and numbers) and -in some cases- digital literacy -but neglects or underestimates multimodal literacy (Kress, 2010) which actually deals with meaning making in a variety of modes. The synchronous functioning of the modes of image, movement, color, gesture, 3D objects, music and sound on a digital screen requires a different type of 'reading' or 'writing', a literacy that entails non-linear and simultaneous processing. As Serafini (2010) pointed out 'this shift from a linguistic focus to a multimodal one requires readers to navigate, design, interpret and analyze texts in new and more interactive ways' (p. 86).Thus, important processes in multimodal literacy involve using and learning Web 2.0 technologies, understanding the combined use of audio and video files, designing and producing digital artifacts, production of storyboards for both information report and narrative using digital photos, graphics or 
drawings, using visual and digital modes combined with text: all used in an interdependent process.

Students' reflection upon study material has been often considered as part of critical thinking, in the sense of engaging in an activity with skeptical criticism; Mezirow's theory on transformative learning on study material involves the use of "subjective reframing" (which entails critical self reflection) and "objective framing" (which entails critical reflection upon other material). Reflective education focused activities contribute significantly to optimizing the impact of teaching (Mckenna, Yalvac, \& Light, 2009), so under this scope the exploration of such activities' use is quite important especially in Higher Education contexts where reconceptualization and application of new knowledge is quite important (Barak, 2006). This paper presents important features of Higher Education students' infographics' as digital artifacts, reflective of their understanding in a study resource; emphasis has been placed on the evaluation of content and aesthetics as the infographics produced have been used as a communication (to their Tutors) tool to reflect their understanding on a HOU provided study resource.

\section{Infographics}

To read and produce multimodal texts, students need to be able to combine traditional literacy practices with the understanding, design and manipulation of different modes of image, graphics, sound and movement with text. Krum (2014) defines infographics as graphic design that combines data visualizations, illustrations, text, and images together into a format that shapes a comprehensive description. Information can be efficiently presented with a minimum explanation, and at the same time, the relationships of the content can be provided, as mentioned by Lester (2011). In other words, infographics offer new ways of engaging a logical sequence in order to present the content in an interesting way (Abilock \& Williams, 2014; Lamb \& Jhonson, 2014; Yildirim, 2017). Despite all the existing research on new technological use in the higher education context, the literature on using infographics in teaching remains limited at best (Mc Kenna et al, 2009). Studies on the best practices in teaching that make use of infographics either as an information-sharing tool or as a method of evaluating students' work are rather scarce (Dunlap \& Lowenthal, 2016; Siricharoen \& Siricharoen, 2015). It is important for educators to understand how students process the information contained in infographics since infographics can provide a way to reach students with varied learning styles, particularly visual learners (Lankow et al., 2012; Smiciklas, 2012).

Visual learners remember best what they see, such as pictures, diagrams, flow charts, timelines, films, and demonstrations. Visual learning presents the relationships between the topics (Hyerle, 1996) whereas the visual depiction is based on four essential elements a) attention is focused on central topics/images, b) main themes radiate as branches from the central image/topic, c) topics of lesser importance are represented by higher level branches, and d) branches connect in a nodal structure (Buzan, 1991). According to literature, incorporating infographics in curriculum or Higher Education courses, is interrelated with what we might call different 'learning styles' though admittedly this is a contested notion - or communication modalities (Fletcher \& Major 2016). Studies have shown that some learners experience greater self-efficacy and even achieve higher course performance when faculty provides resources that cater to various ways of knowing, communicating information, and remembering it (Hawk and Shaw, 2007). Using images in the educational context could also be an important tool to encourage a general visual literacy among all the students (Thomas, Place and Hillyard, 2008), more than just a pedagogical strategy for reaching visual learners. Engaging learners in creating visual artifacts thus helps 
them understand visual culture, or the 'visual construction of the social' which forms part of their often unseen day-to-day experience of the world around them (Mitchell, 2002). Finally, like the creation of arguments in a rhetoric or professional writing course, visual argumentation requires students to engage in important critical analysis of the material that they are learning. Hence, the activity of designing a diagram or a visual representation of an idea can actually help students to engage with an argument, sharpening their rhetorical skills (Danis, 1993).

Infographics can be used as an alternative tool for teaching design and at the same time, as a means to facilitate students' highest achievements in education (Schrock, 2014). Content and form are equally important dimensions in producing digital artifacts such an infographic. The term 'aesthetics' is broadly used to describe the characteristics of the appearance of a design (Palmer \& Dodson, 1996) In particular, it refers to the responses that indicate the degree of discrimination in perception when people are confronted with the design. Exploring the critical analysis of aesthetics in design, or the inter-relationship between aesthetics and product characteristics are quite open in exploration field. Important basic aesthetic properties that could be used for evaluation according to literature are the following: expression, representation and form. Arousing emotions from an observer in an art work (or a design) makes this expressive (Knoop et al, 1998). This emotion may be embedded in the work by an artist (or a designer) on purpose or unintentionally. The content of the art work is connected with the representation criterion, which may be actual, idealized or imagined, while form refers to the structure, organization and composition of an object.

Evaluating aesthetics is often a subjective process which needs definition of specific criteria according to which digital products are evaluated. This happens because the language used to describe aesthetics is rich, very diverse and sometimes fuzzy, where one term may have different meanings for a number of people or many terms can imply similar or the same meaning. To identify commonly accepted aesthetic characteristics and to match these characteristics against basic characteristics of products which can be computable, seems an important challenge in the design field. Shape, composition and physical attributes of any designed product, relate with the affordances of the digital artifact produced. Balance, in the sense of visual equilibrium, as harmony where pleasant effects are created by grouping objects with accordance in each other, makes infographic interesting. Dominance over principality relates the unity of the design with allowing one feature to dominate the rest: the dominant feature may be a distinct, shape, color, material etc. Simplicity, contrast, continuity and structural coherence all relate to an aesthetically evaluated product: avoiding over crowded features to ease focus, creating impact by using light against dark, combining several elements of similar characteristics into one whole mass, supports visual power which is related with stability and strength.

\section{Method}

\subsection{Context: LRM55 Module}

LRM55 Module "Design and Development of Educational Material and Digital Media" is a 14 week duration, English speaking Module of the Post Graduate program "Language Education for Refugees and Migrants " (LRM) (https://www.eap.gr/en/courses/4562-language-education-forrefugees-and-migrants-lrm-2 ) of the Hellenic Open University; LRM55 Module has been fully developed in Moodle platform (HOU Courses platform space), distributed digitally, involving (3) electronic Tutor Student Sessions (TSSs). The LRM program aims at providing students with specialized pedagogical knowledge regarding language learning methodology; students are supported in developing their understanding for theoretical and practical aspects of Second 
Language Learning. However, LRM conceptualizes language as part of the wider communication environment and acknowledges the need to take into consideration the interplay of modes in the meaning making process. Thus, multimodality constitutes one of the core aspects of this new program which aims at raising students' multimodal awareness in various ways (Kitsiou et al, 2019). Especially in the frame of LRM55, multimodality is clearly interweaved with digitality. The objectives of LRM55 module is to train adult professionals in developing small scale educational content in language learning using open source digital tools. Students become acquainted with major instructional design theories, becoming critical thinkers of learning through technology, applying digital and visual literacy skills so as to produce their own, small scale educational material with the use of a plethora of digital tools. This is an obligatory Module accredited with ECTS 10.

\subsection{Research sample and process}

For the specific paper, twelve (12) HOU LRM 55 students have granted permission to process their timeline infographics produced during the $1^{\text {st }}$ study week of LRM 55 Module. During the $1^{\text {st }}$ LRM55 study week, students have been requested to create a diagram/scheme/infogram presenting the most important elements of the digital dossier of Andy as presented in the respective Palfrey \& Gasser (2008) resource by using Piktochart or Camva as the digital tools to design their timeline infographic. The infographic produced, in that sense, has been a reflection of their understanding on the important components of a Digital Dossier as presented in the specific study resource. Students contributing to this research have been mostly female: (11) female and (1) male, mostly secondary school teachers. The instructional process used for reaching the students as visual learners has been to engage in production of visual diagrams that summarize the linkages between the materials (Maal, 2004; Sword, 2004); such concept diagrams offer a visual summary of a topic based on organizing information via hierarchies and categories as in the case of the timeline infographic requested by students.

\subsection{Evaluation Procedure}

Use of questionnaires and rubrics have been found to optimize the quantification of learning strategies, especially in terms of multi-method research (Schellings, 2011), metacognitive aspects (Thomas, Anderson, \& Nashon, 2008), and methodological skills (Mokhtari \& Reichard, 2002; Feldon et al., 2011). The use of rubrics in higher education learning and teaching can work as an essential aid in ensuring that students undertake deep learning and that courses are constructively aligned i.e. the learning outcomes are clearly set out and any form of assessment of teaching content matches such learning outcomes. To evaluate the (12) timeline infographics, two rubrics have been used focusing on content and aesthetics respectively (Kos \& Sims, 2014). The Content and Information rubric focused on the kind of information which has been included in the infographic; important axes of Rubric 1 have been Facts, Graphs, Pictures, Sources. The Design and Aesthetic Rubric has been based on Readability axis, Emphasis, Simplicity and Consistency. The design and esthetic rubric focused on how the infographic looked like. This is quite important since the visualization of an infographic is what sells and communicates the idea. The timeline infographics have been designed by students during a two weeks timeslot.

\section{Results}

\subsection{Content/Information and Design/Aesthetic Rubric}


The following two tables present the evaluation of the (12) infographics according to the Content and Information Rubric (Rubric 1) and the Design and Aesthetic Rubric (Rubric 2). Important criteria for composing the Content and Information Rubric have been the textual component (number of text lines, headings and subheadings excluded), the inclusion of graphs and symbols, the use of pictures and sources which have been used to produce the timeline infographic. The following table presents the characteristics of the 12 infographic timelines according to the Content and Information Rubric:

\begin{tabular}{|c|c|c|c|c|}
\hline & Text (number of lines ) & Graphs- Symbols & Pictures & Sources \\
\hline Info \#1 & 38 lines & 1 & 0 & 1 \\
\hline Info \#2 & 0 lines & 2 & 29 & 0 \\
\hline Info \#3 & 56 lines & 1 & 6 & 0 \\
\hline Info \#4 & 38 lines & $5^{*}$ & $0^{*}$ & 1 \\
\hline Info \#5 & 25 lines & 0 & 5 & 1 \\
\hline Info \#6 & 43 lines & 0 & 1 & 1 \\
\hline Info \#7 & 22 lines & 4 & 1 & 1 \\
\hline Info \#8 & 25 lines & 3 & 0 & 0 \\
\hline Info \#9 & 3 lines & 7 & 0 & 0 \\
\hline Info \#10 & 99 lines & 5 & 15 & 1 \\
\hline Info \#11 & 37 lines & 6 & 0 & 1 \\
\hline Info \#12 & 67 lines & 1 & 8 & 1 \\
\hline
\end{tabular}

Table 1: Collected data on Content and Information Rubric

The second rubric, the Design and Aesthetic Rubric had as a goal to describe the visual design of the twelve (12) collected timeline infographics- based on whether the content has been readable, the points of emphasis addressed in each infographic, the simplicity or complexity in presenting content and whether the design of the infographic has been consistent in terms of color use and design match. The following table presents the analysis of the collected infographics according to the predefined Rubric 2 criteria:

\begin{tabular}{|c|c|c|c|c|c|c|c|}
\hline Readability & $\begin{array}{l}\text { No of } \\
\text { Info (\%) }\end{array}$ & Emphasis & $\begin{array}{l}\text { No of } \\
\text { Info (\%) }\end{array}$ & Simplicity & $\begin{array}{l}\text { No of } \\
\text { Info } \\
(\%)\end{array}$ & Consistency & $\begin{array}{l}\text { No of Info } \\
\text { (\%) }\end{array}$ \\
\hline $\begin{array}{l}\text { Everything (text, } \\
\text { graphs, pictures) is } \\
100 \% \text { readable }\end{array}$ & $58,3 \%$ & $\begin{array}{l}5 \text { or more } \\
\text { points of } \\
\text { emphasis }\end{array}$ & $83.33 \%$ & $\begin{array}{l}\text { All information has } \\
\text { a purpose }\end{array}$ & $33.3 \%$ & $\begin{array}{l}\text { All colors and } \\
\text { the overall } \\
\text { design match }\end{array}$ & $66.6 \%$ \\
\hline $\begin{array}{l}\text { Some parts may be } \\
\text { difficult to read } \\
\text { because of text } \\
\text { color or } \\
\text { backgrounds }\end{array}$ & $25 \%$ & $\begin{array}{l}\text { 3-4 points } \\
\text { of emphasis }\end{array}$ & $16.66 \%$ & $\begin{array}{l}\text { Some } \\
\text { information does } \\
\text { not have a } \\
\text { clear purpose }\end{array}$ & $41.66 \%$ & $\begin{array}{l}\text { A few colors } \\
\text { are out of } \\
\text { place, but } \\
\text { overall fairly } \\
\text { consistent }\end{array}$ & $25 \%$ \\
\hline
\end{tabular}

SECTION A: theoretical papers, original research and scientific articles 


\begin{tabular}{|l|l|l|l|l|l|l|l|}
\hline $\begin{array}{l}\text { Most parts are } \\
\text { readable, but a } \\
\text { large number of } \\
\text { text or graphics are } \\
\text { not }\end{array}$ & $16.66 \%$ & $\begin{array}{l}2 \text { or less } \\
\text { points of } \\
\text { emphasis }\end{array}$ & $0 \%$ & $\begin{array}{l}\text { Quite a bit of } \\
\text { extra } \\
\text { information } \\
\text { without a } \\
\text { purpose }\end{array}$ & $25 \%$ & $\begin{array}{l}\text { Quite a few } \\
\text { colors or } \\
\text { design } \\
\text { choices } \\
\text { do not match }\end{array}$ & $8.33 \%$ \\
\hline
\end{tabular}

Table 2: Collected data on Design and Aesthetic Rubric

\subsection{Infographics' Design \& Aesthetic Characteristics}

HOU students who produced the infographics have not been particularly technologically savvy neither had been a priori provided with guidelines for constructing their infographic whereas some of them have admitted that it has been the first time that they have encountered the term. Students' work showcased some good examples of infographics in the sense of a) organizing in a functional and aesthetic manner the respective content and visuals, b) designing the digital artifact on the basis of balance between text and images. Good examples of infographics involved a) the functional presentation of the summarized reading resource, b) well attended presentation and simple decoration of the artifact. Thus infographics as data visualization tools involve a specific pattern which is hidden behind the complexity of tabular forms of numbers and data and is recognizable when human brain can identify that. In that sense, graphics are not just displays; audience can extract information from and devices to explore information with. For example putting in too much information (or not enough), using inappropriate types for the information provided, and unsuitable charts or graphs and other failures are common.

Regarding Readability important characteristics of a good infographic is the use of fonts and layout, the careful and well laid in the infographic space arrangement of content as well as the use of design which enables easy navigation though the content produced. In this type of infographic all information is readable: the color scheme does not hinder ability to read, the font choice, size and color have been used to make the content legible. As example of such, could be used the following ( with the metadiscription presented in bullets):
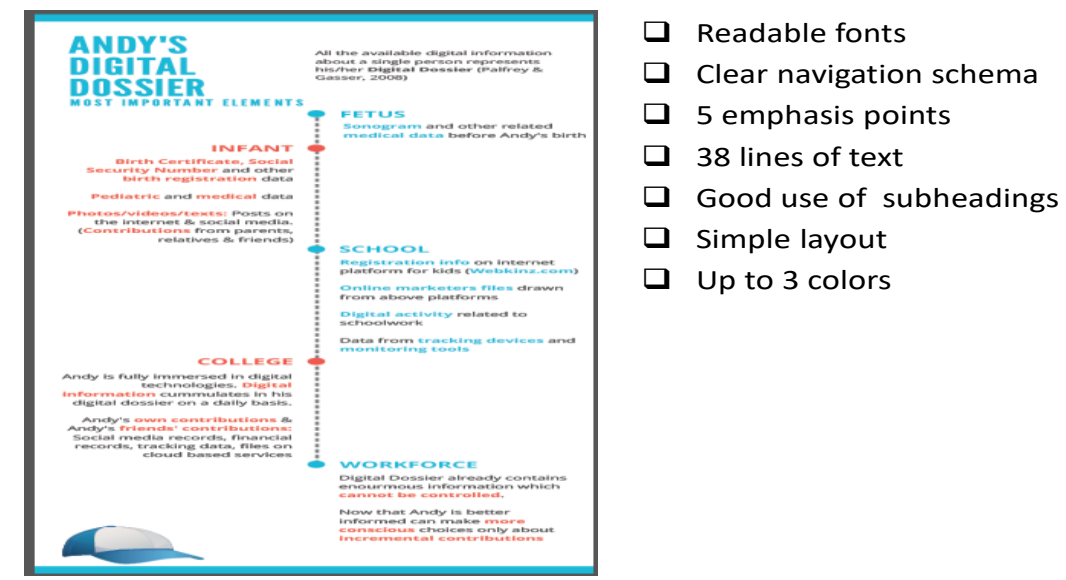

Figure 1: Example of Readability and LRM 55 student's infographic

Regarding Emphasis important characteristics of a good infographic is the clear arrangement of infographic in terms of important sections, clear and good use of emphasis points, homogeneity in content presentation. As example of such could be used the following (with the metadescription presented in bullets): 


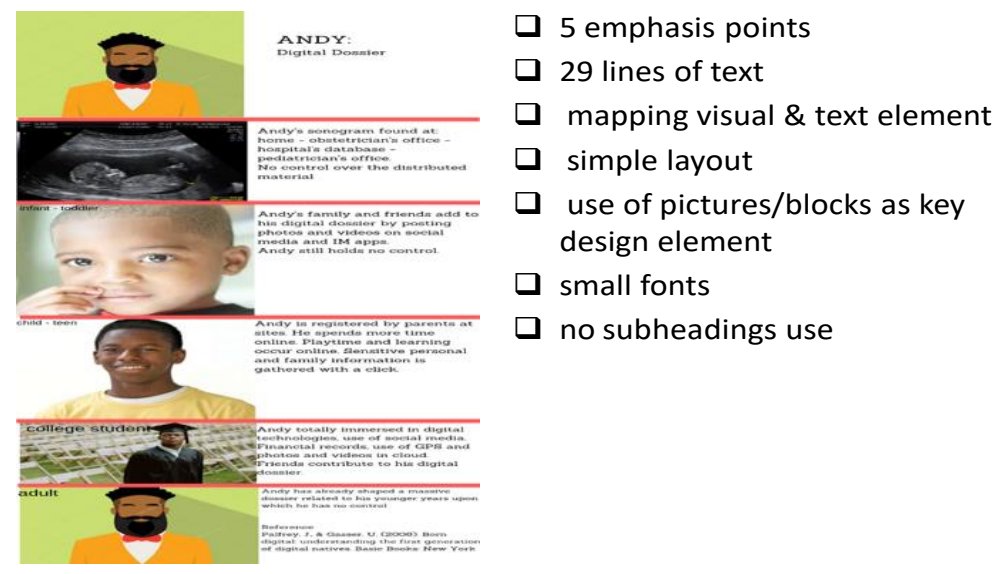

Figure 2: Example of Emphasis and LRM 55 student's infographic

Regarding Simplicity important characteristics of a good infographic is the use of simple layout, the use of a clear structure as a pattern which supports reader in understanding the digital artifact, limited and clearly organized content used, avoidance of using multiple colors. In this kind of infographic all related content has a purpose; space is used effectively (no excess clutter) as well as appropriate use contrast and color has been applied. As example of such could be used the following (with the metadescription presented in bullets):

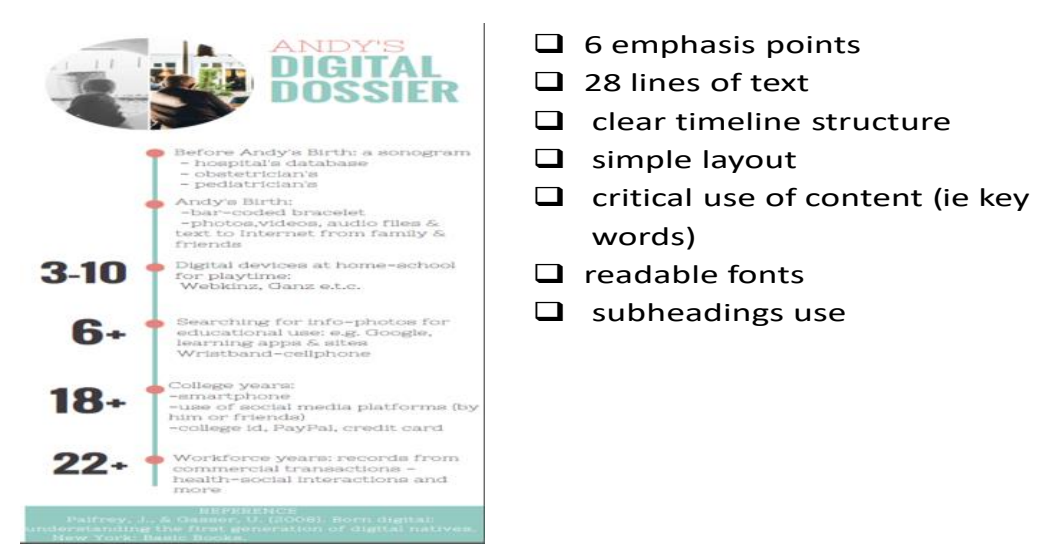

Figure 3: Example of Simplicity and LRM 55 student's infographic

Regarding Consistency important characteristics of a good infographic is the homogeneity in design, well presented structure, systematically, through whole the infographic, clear content organization. In this type of infographic overall colors and design match; the content is easy to follow and overall design facilitates understanding, Hierarchy/organization of data. As example of such could be used the following (with the metadescription presented in bullets): 


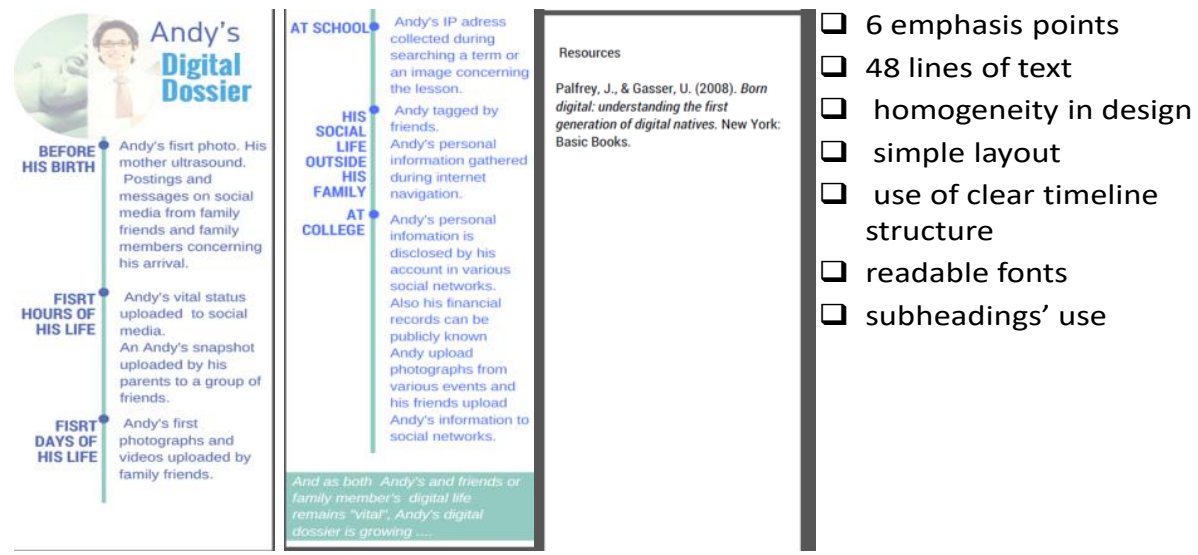

Figure 4: Example of Consistency and LRM 55 student's infographic

The on line infographics creation websites offer a wide range of tools (LRM55 students used Piktochart and Canva) to create an infographic from scratch, but at the same time, the use of templates is available so does not have to create an infographic from scratch. Some students made use of templates: this approach enabled the production of visual appealing infographics but also offered flexibility in the amount of imaginativeness that students could make use of. Students included images, or pictures to present their version on Andy's Digital Dossier, being well receptive of the idea that they could use other forms of communication instead of writing and still communicate ideas. The organization and flow of information, the use of text and colors in terms of design elements and the inclusion of pictures have been important parameters for the production of good infographics as suggested and analysed in the next section of the paper, where the data of Content and Information Rubric is discussed.

\section{Discussion}

Regarding the Content and Information Rubric, the majority of collected artifacts have been quite loaded in text information: the minimum text has been 0- 3 lines whereas there has been an infographic with 99 text lines. There have been infographics with too much information translated in text lines $(99,67,56$ lines) whereas the average of text used has varied from 25 till 35 lines. It seems that students have been mostly acquainted with text literacy instead of visual, so this "safe" approach had an implication on the infographics" design, thus they created heavy in text content infographics. Three (3) students used only (1) symbol/graph for their infographic whereas there have been (2) cases in which no symbol/graph has been used. Data revealed that the symbols' use has also been quite limited whereas only (3) infographics included from 5-7 symbols, identifying a more creative approach in designing the infographics. Disparity has also been traced in the inclusion of pictures: five (5) infographics have not included images at all whereas two (2) have included only 1 picture. The maximum number of images included in this category has been 29 images in an infographic which has been based on the use of images and limited use of text. Though students had to use Palfrey and Gasser 2008 resource (which 
numbers 25 pages in length), not all of them have included this as a basic resource in their infographic design: 4 students have not included this at all in their final product.

Regarding the Design and Aesthetic Rubric, seven (7) of the infographics have been completely readable, whereas the other 5 had problems in reading the content ( 3 due to problems with colors and layout and 2 because a large number of texts and graphics were not readable). Ten (10) of the infographics had more than 5 points of emphasis in their design, finding which indicates the students' effort to construct an infographic based mainly in the basic characteristic of timeline infographics, the presentation of evolution stages over time. Four (4) of the infographics have presented information in a purposeful manner. Five (5) of the 12 infographics though, had not presented information in a quite clear and purposeful manner. The majority of the infographics, eight (8) infographics have been quite consistent in the sense of the overall matching of design and colors, finding which reveals that students even subconsciously had tried to apply aesthetics in their design. There have been examples of infographics which have included different pieces of information (i.e. content, symbols) such as info\#7 and info\#10. All the infographics of this students' group had included a title in the infographic however, there has been a disparity in the way subheadings have been used in terms of systematicity in their use. Regarding aesthetics, some design patterns have revealed that the white background or the palette of light colors has been used by quite a few students as canvas to design the structure of their infographic. The use of long text has also been a negative feature of some infographics (i.e. info \#3, info\#12), distracting the audience from the message conveyed. There have also been infographics which their length has extended over than one page.

It seems that teaching visual literacy basics and competencies in Higher Education is an arising need, coming out of the rapid advent of $21^{\text {st }}$ century skills: young professionals and practitioners is important to obtain mastery in visualizing content, effectively using images, sound and video to produce educational (or in a professional context) content on professional demand and even in the case of teachers, use visual literacy as a means of reflection and enhancing effectiveness in teaching and learning processes. Acknowledging criteria of aesthetics and effective content use in digital design seem prevailing factors in preparing professionals as competent users of visual literacy, adaptable to learning situations that educational future brings forward (Krum, 2013).

Understanding the multimodal ways in which knowledge is presented is important for educators in terms of equipping students with the necessary skills and competencies to become competent both in the production and consumption of multimodal text but also the ability to critically 'read' multimodal texts. It has been evident out of the collected data, that understanding of the Palfrey and Gasser's resource as reflected in the produced infographics has not been the same for all LRM 55 students: differentiations have occurred in the level of detailed (or filtered) content included in the infographics, the color palette and synthesis used in respect with infographic's readability and functionality, the extent of the infographic (from 1 to 4 pages), the clear presentation (or not) of the infographic's scope etc. These all relate with key decisions made by students who acted as knowledge producers: experiencing their skills in multimodal literacy which according to Djonov (2010:119) has to be defined "as design, as an active dynamic process of creating meaning out of multimodal semiotic resources". Not all students have assessed information provided by the Palfrey and Gasser 2008 resource in the same manner; it is important students to be sensitized to the meaning potential and choices afforded in the production of the text, process which actually brings forward an enhanced ability to make deliberate and effective choices in the construction and presentation of knowledge. 


\section{Conclusion}

The use of infographics is an important step towards developing a pedagogical approach that draws on visuals. This paper presented collected data from HOU Module LRM55 ("Design and Development of Educational Material and Digital Design") so as to pinpoint characteristics of students' design work in the context of the Master's course 'Language Learning for Migrants and Refugees". The undertaken by HOU students' design practices regarding the infographics' making, revealed relatively extended use of text, limited use of images and symbols, and a variety of content inclusion from the Palfrey and Gasser (2008) resource which not all of it has been necessary to be included in a data visualization tool such as infographics. Under this scope HOU students' more intense preparation on the design and use of infographics for educational/professional purposes could be an important conclusion derived out of this paper. As there are certain skills to create infographics both technical and literacy based, this data visualization tool could be used to transcend students from consumers to creators of knowledge. Further actions involve the support of HOU students in the official context of the LRM 55 Module in terms of providing guidelines, good practices and examples so as to understand the power of infographics to extend human capacities.

Acknowledgements: The authors would like to cordially thank the LRM 55 students of HLE 1 (Winter 2018a Semester) for their consent on using their designed digital artifacts for writing this paper: without their consent, this work could not be published.

\section{References}

Abilock, D., \& Williams, C. (2014). Recipe for an Infographic. Knowledge Quest, 43 (2), 46-55.

Barak, M. (2006). Instructional principles for fostering learning with ICT: teachers' perspectives as learners and instructors. Education and Information Technologies, 11(2), 121-135.

Buzan, T. (1991). Use both sides of your brain. New York: Plume

Djonov, E.N. (2010). Book review: Carey Jewitt, Technology, literacy and learning: A multimodal approach. Visual Communication, 9(1), 117-125.

Dunlap, J. C., \& Lowenthal, P. R. (2016). Getting graphic about infographics: Design lessons learned from popular infographics. Journal of Visual Literacy, 35(1), 42-59.

Feldon, D.F., Peugh, J., Timmerman, B.E., Maher, M.A., Hurst, M., Strickland, D., Gilmore, J.A., \& Stiegelmeyer, C. (2011). Graduate students' teaching experiences improve their methodological research skills. Science, 333, 1037-1039

Fletcher, D, T, \& Major, D. A. (2006). The effects of communication modality on performance and self ratings of team work components, Journal of Computer Mediated Communication, 11(2), 557-576

Hawk, T. F., \& Shah, A. J. (2007). Using learning style instruments to enhance student learning. Decision Sciences Journal of Innovative Education, 5(1), 1-19. doi:10.1111/j.1540-4609.2007.00125.x

Kitsiou, R., Makri, A., \& Papadopoulou, M. (2019). Multimodal awareness raising in an online second language acquisition postgraduate program. Oral presentation in the A-MODE International Conference 'Approaches to Multimodal Digital Environments: from theories to practices', Rome 20-22/6/2019

Knoop W.G., Breemen E.J.J. van, Horváth I., Vergeest, J.S.M., \& Pham B. (1988). Towards Computer Supported Design for Aesthetics. In the $31^{\text {st }}$ ASATA - International Symposium on Automotive Technology and Automation, Dusseldorf, Germany, 2-5 June 1998

Kos, B. A., Sims, E. (2014). Infographics: The New 5-Paragraph Essay. In 2014 Rocky Mountain Celebration of Women in Computing.Laramie, WY, USA.

Krum, R., (2013). Cool infographics: Effective communication with data visualization and design. Indianapolis: John Wiley \& Sons, Inc.

Kress, G. (2010). Multimodality: A social semiotic approach to contemporary communication. London \& New York: Routledge.

Lamb, A., Jhonson, L., (2014). Infographics Part I: Invitations to Inquiry. Teacher Librarian 41(4), 54-58

SECTION A: theoretical papers, original research and scientific articles 
Lankow, J., Ritchie, J., \& Crooks, R. (2012). Infographics: The power of visual storytelling. Wiley.

Mckenna, A.F., Yalvac, B., \& Light, G.J. (2009). The role of collaborative reflection on shaping engineering faculty teaching approaches. Journal of Engineering Education, 98, 17-26.

Mitchell, W. J. (2002). Showing seeing: A critique of visual culture. Journal of Visual Culture, 1(2), 165-181. doi:10.1177/147041290200100202.

Thomas, G.P., Anderson, D., \& Nashon, S. (2008). Development of an instrument designed to investigate elements of science students' metacognition, self-efficacy and learning processes: the SEMLI-S. International Journal of Science Education, 30(13), 1701-1724.

Mokhtari, K., \& Reichard, C. (2002). Assessing students' metacognitive awareness of reading strategies. Journal of Educational Psychology, 94, 249-259.

Palmer, J., Dodson, M., (1996). Design and Aesthetics: A Reader. London: Routledge

Serafini, F. (2010). Reading multimodal texts: Perceptual, structural and ideological perspectives. Children's Literature in Education, 41, 85-104. doi:10.1007/s10583-010-9100-5

Siricharoen, W. V., \& Siricharoen, N. (2015). How infographic should be evaluated? In the Proceedings of the 7th International Conference on Information Technology (ICIT 2015), (pp. 558-564). Retrieved from https://goo.gl/5QUWHT.

Smiciklas, M. (2012). The power of infographics: Using pictures to communicate and connect with your audiences. Que Publishing.

Thomas, E., Place, N., \& Hillyard, C. (2008). Students and teachers learning to see: Part 1: Using visual images in the college classroom to promote students' capacities and skills. College Teaching, 56(1), 23-27.

Yildirim, S. (2017). Approaches of designers in the developed educational purposes of infographics' design processes. European Journal of Education Studies, 3(1), 249-284. 